\title{
Pengaruh Penggunaan Konseling Kelompok Trait and Factor Terhadap Ketepatan Pemilihan Jurusan Siswa
}

\author{
M. Fahli Zatrahadi, Neviyarni, Yeni Karneli, Netrawati \\ Bimbingan dan Konseling, Universitas Negeri Padang \\ Jl. Prof. Dr. Hamka, Air Tawar Padang, Sumatera Barat \\ E-mail: hadifahli87@gmail.com
}

\begin{abstract}
Article Info
Abstract

Received Oktober 2021

Accepted November 2021

Published November 2021

Keywords:

accuracy of majors

selection, group

counseling, trait and factor

approach

The choice of majors at school is part of career exploration as preparation for entering the world of professional work. However, choosing a major can be confusing for students. This study aims to determine the effect of using trait and factor group counseling on the accuracy of majors selection. The research uses a quantitative approach with the correlational method. The sample in this study were 91 students of class XII who had made the selection of majors. Data were analyzed using regression analysis with the help of SPSS 25 for Windows. The results show that there is no significant effect between the use of trait and factor group counseling on the accuracy of majors selection.
\end{abstract}

\begin{abstract}
Abstrak : Pemilihan jurusan di sekolah merupakan bagian ekplorasi karir sebagai persiapan memasuki dunia kerja profesional. Namun, pemilihan jurusan dapat menjadi hal yang membingungkan bagi siswa. Penelitian bertujuan untuk mengetahui pengaruh penggunaan konseling kelompok trait and factor terhadap ketepatan pemilihan jurusan. Penelitian menggunakan pendekatan kuantitaif dengan metode korelasional. Sampel dalam penelitian ini adalah 91 orang siswa kelas XII yang telah melakukan pemilihan jurusan. Data dianalisis menggunakan analisis regresi dengan bantuan SPSS 25 for Windows. Hasil menunjukan bahwa tidak terdapat pengaruh yang signifikan antara penggunaan konseling kelompok trait and factor terhadap ketepatan pemilihan jurusan.
\end{abstract}

Kata Kunci: ketepatan pemilihan jurusan, konseling kelompok, pendekatan trait and factor

C2021 Jurusan Ilmu Pendidikan, FKIP Universitas Lampung 


\section{PENDAHULUAN}

Perkembangan karir yang terjadi di abad 20 menuntut pekerja untuk menjadi pembelajar sepanjang hayat agar mampu membuktikan kerja profesional dan mampu beradaptasi dengan lingkungan kerja (Rad et al., 2015). Individu memerlukan pengembangan karir sejak dini agar mampu bersaing dalam dunia kerja profesional. Holland (1997) menyatakan individu melakukan eksplorasi terhadap karir yang akan ia tekuni. Proses ini terjadi di masa sekolah.

Lingkungan sekolah berperan dalam proses perencanaan karir siswa (Saifuddin, 2018). Siswa memperoleh pengetahuan dan keterampilan dari guru yang kemudian mempengaruhi cara siswa merencanakan pendidikan di SMA termasuk pemilihan jurusan. Perencanaan karir yang baik akan mempengaruhi kinerja individu dalam penyelesaian pekerjaan. Hal ini sejalan dengan penelitian Massie (2015) bahwa perencanaan karir mempengaruhi kinerja pegawai. Ini menunjukan pentingnya penyiapan karir pada siswa.

Bentuk perencanaan karir di sekolah menengah atas berupa pemilihan jurusan yang sesuai dengan tujuan karir siswa di masa depan. Pengambilan keputusan untuk memilih minat jurusan dalam suatu sekolah harus akurat (Wahyuni, 2017). Namun, pemilihan jurusan sering kali menjadi kesulitan tersendiri bagi siswa. Penelitian Wulandari (2013) mengungkap alasan pemilihan jurusan pada siswa yaitu pertimbangan nilai. Kurang dipenuhinya persyaratan nilai akademis pada jurusan tertentu berdampak pada pemilihan jurusan yang tidak sesuai dengan minat siswa sehingga mempengaruhi proses dan hasil belajar siswa (Perta, 2021). Lebih lanjut, mempengaruhi pemilihan jurusan di perguruan tinggi (Hikmah, 2018). Alasan lain yaitu coba-coba atau mengikut pilihan teman terhadap jurusan yang dipilih (Muwakhidah \& Pravesti, 2017). Hal ini disebabkan oleh adanya kebingungan siswa dalam menentukan jurusan. Sejalan dengan itu, Sugiati dan Fitri (2020) menyatakan siswa di usia remaja cenderung menentukan keputusan karir secara bimbang dan ragu-ragu.

Dalam setting pendidikan, upaya membantu siswa dalam pemilihan jurusan dapat dilakukan oleh guru bimbingan dan konseling. Sesuai dengan Permendikbud Nomor 111 Tahun 2014 bahwa fungsi bimbingan dan konseling 
adalah pencegahan, perbaikan atau penyembuhan, pemeliharaan dan pengembangan. Penerapan fungsi bimbingan dan konseling dalam upaya pengembangan karir bertujuan untuk memastikan siswa mencapai kematangan karir.

Salah satu layanan bantuan yang dapat diberikan untuk pemilihan jurusan adalah konseling kelompok (Sugiati \& Fitri, 2020). Beberapa peneliti menekankan pentingnya menganalisis interaksi antara karakteristik individu dan faktor lingkungan kerja melalui pendekatan trait and factor (Rad et al., 2015). Pendekatan trait and factor didefinisikan sebagai konseling direktif dengan asumsi kesesuaian antara sifat dan faktor individu akan melahirkan kesuksesan karir pada individu (Churnia et al., 2021). Asumsi-asumsi inilah yang mendasari lahirnya teori sifat dan faktor yang merupakan teori pilihan karir (Woods, Stephen A. Edmonds, Grant W. Hampson \& Lievens, 2020).

Konseling kelompok trait and factor telah digunakan secara luas untuk menangani permasalahan pemilihan jurusan. Hasil penelitian Sulistyowati dan Mahmudi (2015) menunjukan konseling trait and factor berpengaruh signifikan terhadap ketepatan pemilihan jurusan. Konseling kelompok trait and factor berpengaruh terhadap kematangan karir siswa (Murisal et al., 2018; Sugiati \& Fitri, 2020). Selain itu, konseling trait and factor baik secara individual maupun kelompok memberikan dampak positif pada pemilihan program belajar dan program kerja pada siswa (Mahfud, 2016; Sulistyowati \& Mahmudi, 2015).

Berdasarkan beberapa hasil penelitian dapat disimpulkan bahwa pemilihan jurusan dan penggunaan konseling kelompok trait and factor memiliki keterkaitan. Namun, setiap sekolah memiliki karakteristik siswa yang berbeda. Oleh karenanya, perlu adanya penelitian lain untuk mengetahui pengaruh penggunaan konseling kelompok trait and factor terhadap pemilihan jurusan di lokasi sekolah yang berbeda. Hal ini penting dilakukan agar menjadi data yang memvalidasi dampak konseling kelompok trait and factor terhadap pemilihan jurusan.

\section{METODE}

\section{Desain penelitian}

Penelitian menggunakan desain korelasional dengan tujuan mengetahui pengaruh penggunaan konseling kelompok trait and factor terhadap ketepatan 
pemilihan jurusan dan memprediksi seberapa jauh perubahan nilai ketepatan pemilihan jurursan, bila nilai penggunaan konseling kelompok trait and factor diubah-ubah.

\section{Populasi dan sampel}

Populasi dalam penelitian ini adalah seluruh siswa kelas XII di SMAN 12 Pekanbaru. Siswa kelas XII merupakan kelas yang telah menekuni jurusan di sekolah menengah atas. Oleh karena itu, kelas XII menjadi sasaran subjek penelitian. Sampel penelitian berjumlah 91 siswa yang diambil secara acak.

\section{Instrumen penelitian}

Data diperoleh menggunakan bantuan google form berupa skala penggunaan konseling kelompok trait and factor yang berjumlah 10 item dan ketepatan pemilihan jurusan berjumlah 11 item. Masing-masing skala memiliki lima alternatif jawaban. Instrumen telah diuji validitas dan reliabilitas sehingga layak untuk digunakan sebagai alat pengumpul data.

\section{Analisis data}

Data dianalisis menggunakan regresi liniear sederhana dengan menggunakan bantuan software SPPS 25 for windows.

\section{HASIL DAN PEMBAHASAN}

Untuk melakukan analysis simple linear regression terlebih dahulu dilakukan uji asumsi normalitas dan liniearitas. Pengujian normalitas menggunakan uji One Sample Kolmogorov-Smirnov Test untuk membuktikan bahwa data kedua variabel berdistribusi normal. Hasil pengujian One Sample Kolmogorov-Smirnov Test disajikan pada Tabel 1.

Tabel 1. One-Sample Kolmogorov-Smirnov Test

\begin{tabular}{lll}
\hline $\mathrm{N}$ & & Unstandardized Residual \\
\hline Normal Parameters ${ }^{\mathrm{a}, \mathrm{b}}$ & Mean & 91 \\
\cline { 2 - 3 } & Std. Deviation & .0000000 \\
\hline Most Extreme Differences & Absolute & .079 \\
\cline { 2 - 3 } & Positive & .064 \\
\cline { 2 - 3 } & Negative & -.079 \\
\hline Test Statistic & & .079 \\
\hline Asymp. Sig. (2-tailed) & & $.200^{\mathrm{c}, \mathrm{d}}$ \\
\hline
\end{tabular}


Tabel 1 menunjukan bahwa perolehan nilai sig. (2-tailed) sebesar 0.200 lebih besar dari 0.05 maka dapat disimpulkan bahwa nilai residual berdistribusi normal. Selanjutnya dilakukan pengujian linearitas yang dijadikan pada Tabel 2.

Tabel 2. ANOVA

\begin{tabular}{|c|c|c|c|c|c|c|c|}
\hline & & & Sum of Squares & $\mathrm{df}$ & Mean Square & $\mathrm{F}$ & Sig. \\
\hline \multirow{5}{*}{$\begin{array}{l}\text { Pemilihan } \\
\text { Jurusan * } \\
\text { Trait and } \\
\text { Faktor }\end{array}$} & Between & (Combined) & 1520.405 & 18 & 84.467 & 3.045 & .000 \\
\hline & Groups & Linearity & 60.620 & 1 & 60.620 & 2.185 & .144 \\
\hline & & $\begin{array}{l}\text { Deviation from } \\
\text { Linearity }\end{array}$ & 1459.784 & 17 & 85.870 & 3.095 & .061 \\
\hline & Within Gro & ups & 1997.551 & 72 & 27.744 & & \\
\hline & Total & & 3517.956 & 90 & & & \\
\hline
\end{tabular}

Tabel 2 menunjukan hasil pengujian linearitas memperoleh nilai penyimpangan koefisien data dari linieritas sig. $>0.05$ atau 0.061 lebih besar dari 0.05 yang menunjukkan bahwa terdapat hubungan linier yang signifikan antar variabel. Setelah dilakukan uji asumsi normalitas dan linieritas sebagai syarat untuk melakukan analisis regresi linier sederhana, diperoleh bahwa data terdistribusi normal dan linier. Selanjutnya dilakukan analysis simple linear regression untuk melihat adanya pengaruh yang signifikan antara variabel penggunaan konseling kelompok trait and factor terhadap variabel ketepatan pemilihan jurusan pada siswa, data disajikan pada Tabel 3.

Tabel 3. Model Summary

\begin{tabular}{ll|l|c|r} 
Model & $\mathrm{R}$ & R Square & $\begin{array}{c}\text { Adjusted R } \\
\text { Square }\end{array}$ & $\begin{array}{c}\text { Std. Error of } \\
\text { the Estimate }\end{array}$ \\
\hline 1 & $.131^{\mathrm{a}}$ & .017 & .006 & 6.233 \\
\hline a. Predictors: (Constant), X
\end{tabular}

Tabel 3 menunjukan nilai korelasi antara variabel penggunaan konseling kelompok trait and factor dan variabel ketepatan pemilihan jurusan pada kolom $\mathrm{R}$ yaitu sebesar 0,131 dan koefisien determinasi (R Square) sebesar 0,017 yang menandakan bahwa besarnya variabel penggunaan konseling kelompok trait and factor terhadap variabel ketepatan pemilihan jurusan adalah sebesar $1,7 \%$. Selanjutnya, untuk memastikan apakah koefisien regresi tignifikan atau tidak dapat melakukan uji hipotesis. Nilai koefisien disajikan pada Tabel 4. 
Tabel 4. Coefficients ${ }^{a}$

\begin{tabular}{|c|c|c|c|c|}
\hline $\begin{array}{r}\text { Unstan } \\
\text { Coeff }\end{array}$ & $\begin{array}{l}\text { ardized } \\
\text { ients }\end{array}$ & $\begin{array}{l}\text { Standardized } \\
\text { Coefficients }\end{array}$ & & \\
\hline $\mathrm{B}$ & Std. Error & Beta & $\mathrm{t}$ & Sig. \\
\hline 32.807 & 5.323 & & 6.163 & .000 \\
\hline .165 & .132 & .131 & 1.249 & .215 \\
\hline
\end{tabular}

a. Dependent Variable: Pemilihan jurusan

Adapun yang menjadi dasar pengambilan keputusan analisis regresi dengan melihat pada nilai signifikansi dengan ketentuan:

a. Jika nilai siginifikan lebih kecil dari probabilitas 0,05 artinya ada pengaruh penggunaan konseling kelompok trait and factor terhadap variabel ketepatan pemilihan jurusan.

b. Jika nilai signifikansi lebih besar dari probabilitas 0,05 artinya tidak ada pengaruh penggunaan konseling kelompok trait and factor terhadap variabel ketepatan pemilihan jurusan.

Berdasarkan Tabel 4 diperoleh nilai signifikansi $0.215>0.05$ dari hasil analisis tersebut menunjukkan bahwa tidak terdapat pengaruh yang signifikan antara penggunaan konseling kelompok trait and factor terhadap ketepatan pemilihan jurusan. Hal ini berbeda dengan hasil penelitian Sulistyowati dan Mahmudi (2015) ada pengaruh bimbingan dan konseling trait and factor terhadap ketepatan pemilihan jurusan. Perbedaan dapat terjadi karena adanya perbedaan karakteristik subjek penelitian.

Pemilihan jurusan di sekolah dapat dipengaruhi oleh berbagai faktor. Intelegensi dan minat menjadi salah satu faktor yang memengaruhi pengambilan keputusan jurusan. Pengambilan putusan tentang pemilihan jurusan akan lebih baik jika mempertimbangkan kemampuan intelegensi agar ketika menjalani proses belajar, siswa dapat melalui proses tersebut tanpa hambatan dan memperoleh prestasi yang memuaskan (Rufaidah, 2015).

Hasil penelitian Rahmayu dan Serli (2018) menunjukan bakat, minat, kualitas jurusan dan peluang karir dimana kriteria bakat berada adalah faktor yang paling penting bagi siswa dalam memilih jurusan. Dariyo (2004) menyatakan hal-hal yang berkaitan dengan karakteristik kepribadian individu dapat mempengaruhi seseorang dalam memilih jurusan pendidikan lanjutan seperti bakat, minat, motivasi dan intelektual. Sejalan dengan itu, penelitian 
Nelissa et al. (2018) menunjukan faktor kepribadian memiliki pengaruh paling besar dalam pemilihan jurusan, kemudian bimbingan orangtua dan teman sebaya.

Siswa mungkin merasa ragu untuk memilih suatu jurusan. Guru bimbingan dan konseling dapat memberikan layanan untuk membantu siswa menurunkan keraguan dalam memilih jurusan. Konseling dengan trait and factor dapat meningkatkan keraguan siswa dalam pemilihan jurusan (Atli, 2016). Selain melalui proses konseling, pemilihan jurusan menggunakan berbagai sistem pendukung seperti logika fuzzy, Weight Aggregated Sum Product Assesment (WASPAS), Simple Additive Weighting (SAW) (Mufizar et al., 2016; Rustamaji \& Inayati, 2008; Sianturi et al., 2018). Penggunaan sistem pendukung dapat membantu proses pemilihan jurusan agar sesuai dengan kebutuhan siswa.

\section{KESIMPULAN}

Pemilihan jurusan merupakan bagian penting dalam pendidikan siswa. Jurusan di sekolah hendaknya sejalan dengan bidang yang akan ditekuni di perguruan tinggi atau dunia kerja. Hal ini penting agar siswa mampu berkembang sesuai kompetensi yang dimilikinya sehingga mampu mencapai karir yang baik. Penggunaan konseling kelompok dengan pendekatan trait and factor dapat menjadi alternatif yang bisa digunakan guru bimbingan dan konseling untuk membantu siswa yang mengalami keraguan dalam memilih jurusan. Namun, pengaruh penggunakan konseling dengan pendekatan trait and factor tidak sama antara siswa satu sama lain. Perbedaan karakteristik siswa menjadikan hasil yang berbeda pula.

\section{DAFTAR PUSTAKA}

Atli, A. (2016). The effects of trait-factor theory based career counseling sessions on the levels of career maturity and indecision of high school students. Universal Journal of Educational Research, 4(8), 1837-1847. https://doi.org/10.13189/ujer.2016.040813

Churnia, E., Afdal, A., \& Yusuf, A. M. (2021). Analysis of student career maturity using holland' $\mathrm{s}$ theory. SCHOULID: Indonesian Journal of School Counseling, 6(2), 102-111.

Dariyo, A. (2004). Psikologi perkembangan dewasa muda. Jakarta: Grasindo. 
Hikmah, A. N. (2018). Pengaruh latar belakang jurusan di sma terhadap pemilihan jurusan di perguruan tinggi (Studi Kasus Fakultas Ilmu Tarbiyah dan Keguruan UIN Syarif Hidayatullah Jakarta Angkatan 2015. UIN Syarif Hidayatullah Jakarta.

Holland, J. L. (1997). Making vocational choices: A theory of vocational personalities and work environments (3rd ed.). Odessa, FL: Psychological Assessment Resources.

Mahfud, M. (2016). Konseling trait and factor bagi siswa yang kesulitan dalam memilih program belajar. Jurnal Fikroh, 9(2), 125-143.

Massie, R. (2015). Pengaruh perencanaan karir, pelatihan dan Pengembangan karir terhadap kinerja pegawai pada Museum Negeri Provinsi Sulawesi Utara. Jurnal Berkala Ilmiah Efisiensi, 15(5), 635-645.

Mufizar, T., Anwar, D. S., \& Aprianis, E. (2016). Sistem Pendukung keputusan pemilihan jurusan dengan menggunakan metode SAW Di SMA 6 Tasikmalaya. Voice Of Informatics, 5(1), 1-13. http://voi.stmiktasikmalaya.ac.id/index.php/voi/article/view/5/2

Murisal, M., Neviyarni, N., Yusuf, M., \& Mudjiran, M. (2018). Development of group counseling model with trait and factor approach to increase maturity of students career choices. International Conferences on Education, Social Sciences and Technology, 774-780. https://doi.org/10.29210/20181113

Muwakhidah, M., \& Pravesti, C. A. (2017). Keefektifan konseling kelompok cognitive behavior therapy untuk mengurangi keraguan pengambilan keputusan karier siswa sekolah menengah kejuruan. Jurnal Kajian Bimbingan Dan Konseling, 2(2), 66-75. https://doi.org/10.17977/ um001v2i22017p066

Nelissa, Z., Astuti, S., \& Martunis, M. (2018). Identifikasi Faktor yang mempengaruhi siswa dalam proses pemilihan jurusan pendidikan lanjutan (Studi pada Siswa Kelas XI SMA Negeri 5 Banda Aceh). JPPI (Jurnal $\begin{array}{llll}\text { Penelitian Pendidikan } & \text { Indonesia), } & 48 .\end{array}$ https://doi.org/10.29210/02018198

Perta, W. P. (2021). Dampak pemilihan jurusan terhadap belajar Siswa Di SMA Negeri 1 Batusangkar. Institut Agama Islam Negeri (IAIN) Batusangkar.

Rad, D. V. B. T., Kelemen, G., Alina, R., \& Visztenvelt, A. (2015). Career counseling strategies- a practical handbook (Issue November). Romania: Erasmus What really matters project,. https://www.researchgate.net/profile/Dana_Rad/publication/283722773_Car eer_counseling_strategies___a_practical_handbook/links/5645061308ae 451880a8ab4b/Career-counseling-strategies-a-practical-handbook.pdf? origin=publication_detail

Rahmayu, M., \& Serli, R. K. (2018). Sistem Pendukung keputusan pemilihan jurusan pada smk putra nusantara jakarta menggunakan metode analytical hierarchy process (Ahp). Simetris: Jurnal Teknik Mesin, Elektro Dan Ilmu Komputer, $9(1), \quad 551-564 . \quad$ https://jurnal.umk.ac.id/ index.php/simet/article/view/2022 
Republik Indonesia. (2014). Peraturan Menteri Pendidikan dan Kebudayaan Nomor 111 Tahun 2014 tentang Bimbingan dan Konseling Pada Pendidikan Dasar Dan Pendidikan Menengah.

Rufaidah, A. (2015). Pengaruh Intelegensi dan minat siswa terhadap putusan pemilihan jurusan. Jurnal Ilmiah Pendidikan, 2(2), 143. https://journal.lppmunindra.ac.id/index.php/Faktor/article/view/379

Rustamaji, H. C., \& Inayati, Y. (2008). Sistem pendukung keputusan pemilihan jurusan di SMU dengan logika fuzzy. Seminar Nasional Informatika, 213218.

Saifuddin, A. (2018). Kematangan karier: teori dan strategi memilih jurusan dan merencanakan karier. Yogyakarta: Pustaka Pelajar.

Sianturi, M., Tarigan, J., Rizanti, N. P., \& Cahyadi, A. D. (2018). Sistem pengambilan keputusan pemilihan jurusan terbaik pada smk menerapkan metode weight aggregated sum product assesment ( WASPAS ). Seminar Nasional Sains \& Teknologi Informasi (SENSASI), 10(20), 160-164.

Sugiati, J., \& Fitri, S. (2020). Pengaruh konseling kelompok dengan pendekatan trait and factor terhadap kematangan karir siswa kelas XII SMAN 34 Jakarta. Insight: Jurnal Bimbingan Dan Konseling, 9(1), 1-7.

Sulistyowati, I. N., \& Mahmudi, I. (2015). Pengaruh bimbingan dan konseling trait and factor dan pemahaman potensi diri terhadap ketepatan pemilihan jurusan siswa kelas IX SMPN 5 Kota Madiun. Counsellia: Jurnal Bimbingan Dan Konseling, 5(1), 33-46.

Wahyuni, A. (2017). Sistem pendukung keputusan pemilihan jurusan Di Sekolah Menengah Kejuruan 1 Cengkareng Jakarta. Jurnal Interkom: Jurnal Publikasi Ilmiah Bidang Teknologi Informasi Dan Komunikasi, 12(3), 4-13. https://doi.org/10.35969/interkom.v12i3.9

Woods, Stephen A. Edmonds, Grant W. Hampson, S. E., \& Lievens, F. (2020). How our work influences who we are: testing a theory of vocational and personality development over fifty years. Journal of Research in Personality, 85, 103930.

Wulandari, I. S. (2013). Alasan pemilihan jurusan pada siswa sekolah menengah kejuruan (studi kasus di SMK Negeri 3 Sukoharjo Tahun 2012). Universitas Sebelas Maret. 